\title{
Análise de correspondência aplicada a preposições sobre a eficiência e eficácia do processo de compras públicas a partir da percepção de diferentes atores envolvidos
}

\author{
Public procurement in brazilian universities: analysis \\ of correspondence on applied to prepositions \\ efficiency and effectiveness from different players \\ involved perception
}

Isaac Gezer Silva De Oliveira ${ }^{1}$

\section{Resumo}

O país busca aperfeiçoar suas compras com economia e efetividade para que suas aquisições atendam às demandas do Estado de maneira efetiva e haja adequada aplicação das verbas públicas. Perante esse contexto, o trabalho analisa, na percepção dos diferentes atores das compras públicas, a atuação, a eficiência e a qualidade dos processos licitatórios no âmbito de duas instituições federais de ensino. A pesquisa enveredou na exposição de manifestações legislativas, características do modelo burocrático e do modelo gerencialista para confrontá-las com as dimensões do conhecimento, eficiência e eficácia percebidas pelos atores sociais das instituições analisadas. Os dados foram obtidos a partir da observação direta em processos de licitação e por meio de questionários aplicados aos atores sociais envolvidos. Após a coleta dos dados, foi verificada a consistência interna, a partir do Alfa de Cronbach, para validação dos questionários. Então, tabularamse os dados a partir de análise estatística descritiva e análise de correspondência (ANACOR). Os resultados alcançados demonstram que os preceitos da teoria da burocracia são eivados nos processos de licitação das instituições, todavia, devemse buscar maneiras de aperfeiçoá-la e atenuar disfunções encontradas em seus trâmites e treinamento adequado a todos envolvidos no processo, além de aliar esse modelo com planejamento adequado e boas práticas de gestão, a fim de tornar não

Mestre em Ciências Contábeis, Instituto Federal do Espírito Santo. Servidor no Instituto Federal do Espírito Santo.E-mail: isaacgezer@gmail.com 
somente eficiente, mas também melhorar sua eficácia, à luz da nova gestão pública e dos preceitos de governança pública.

Palavras-chave: Licitações. Burocracia. Eficiência. Eficácia.

\section{Abstract}

The country aims to improve your purchases with economy and effectiveness for their purchases meet the demands of the state effectively, and there is adequate application of public funds. Against this background the present work to analyze, in the perception of the different actors of the buying public, the performance, efficiency and quality of procurement processes under two federal institutions of education. Research embarked on exposure legislative manifestations, characteristics of the bureaucratic model and managerial model to compare them to the dimensions of knowledge, efficiency and effectiveness perceived by the social actors of the analyzed institutions. Data were obtained from the direct observation in bidding processes and through questionnaires applied to the social actors involved. After collecting the data to internal consistency was verified from the alpha cronbach, for validation of the questionnaires and then tabulated them data from descriptive statistical analysis and correspondence analysis. The results obtained demonstrate that the precepts of bureaucracy theory are riddled in bidding processes of the institutions, but must be sought ways to improve it and mitigate anomalies identified in their procedures and adequate training to all involved in the process as well as combining this model with proper planning and good management practices in order to become not only efficient, but also improve its effectiveness, the light of the new public management and public governance principles.

Keywords: Public procurement. Bureaucracy. Efficiency. Effectiveness.

\section{Introdução}

Compras públicas são aquisições de bens e serviços para prover demandas de cumprimento das funções do Estado, tais como saúde, educação e segurança, dentre outras. Elas exercem papel de especial relevância em virtude de sua representatividade na economia dos países. São crescentes os dispêndios com compras públicas, seja para investimento ou com despesas correntes. Desse modo, é necessário que governos tenham sistemas de compras eficientes a fim de garantir alocação equilibrada de recursos, isso porque são gerados em sua 
maioria através dos impostos. Logo, a destinação dada a essa renda pública deve ser responsável, então aquisição no serviço público só pode vir acompanhada do princípio da economicidade acoplado à eficiência.

Ao longo dos tempos, governos promoveram normas para aumentar a eficiência de suas aquisições. Na administração pública brasileira, tais aquisições de bens e serviços são realizadas por meio do procedimento de compra conhecido como processo licitatório regulamentado por normas específicas.

Essas normas se estendem não somente à administração direta (presidência da república e ministérios), mas também à indireta (autarquias, fundações públicas, empresas públicas, sociedades de economia mista e outras entidades controladas pela União, Estado, Distrito Federal e Município).

A licitação pública tem por finalidade garantir os princípios da administração publica, bem como acatar a proposta mais vantajosa, proporcionando assim a melhoria dos serviços prestados à sociedade.

Sendo assim, a licitação, além de garantir que bens e serviços sejam adquiridos de forma legal pelos órgãos, procura também ser resposta viável no controle de gastos governamentais, a fim de proporcionar à administração aquisição ou prestação de serviço menos oneroso e com melhor qualidade.

$\mathrm{Na}$ administração privada, a grande competitividade e as constantes mudanças do sistema capitalista impulsionam as empresas a valorizarem primordialmente suas aquisições. Embora estas sejam realizadas em caráter menos formal que nas entidades públicas, buscam novas ferramentas e estratégias na gestão de compras. Isso porque injetar melhorias para adquirir produtos e serviços mais econômicos e de qualidade representa minorar custos. Posturas como essas implicam gestão otimizada, porque boas aquisições podem representar início de ciclos produtivos eficazes.

Não diferente, na administração pública, as compras são de grande importância, pelo fato de ser a partir delas que se fomentam 
suprimentos para a realização de atividades, desde as básicas às essenciais. Aquisições também desenvolvem as atividades comerciais do Estado; além disso, envolvem ações relativas à administração de finanças públicas, potencializando a adequada distribuição destas.

A nova concepção do Estado, oriunda do processo de globalização econômico ocorrido na década de 1980, possui como característica a redução de gastos, a introdução de modelos gerenciais no contexto da gestão pública, desgastada por sua ineficiência, lentidão, excesso de burocracia e alto custo de manutenção da máquina administrativa (FREITAS; MALDONADO, 2013).

Oliveira (2008) destaca que a modernização das compras públicas representa um grande potencial para o Estado, ao passo que se relaciona com a formação de poupança, com a redução de custos, oportunidade de modernização da máquina administrativa e contribuição para a competitividade econômica do país.

Compreende-se, dessa forma, que é necessário buscar meios de aproximar o processo licitatório às características de uma efetiva administração moderna, à luz dos princípios constitucionais e das novas demandas que surgem em todo momento em virtude dos avanços tecnológicos e disputas de mercados.

Nesse sentido, o estudo buscou compreender a percepção dos diferentes atores envolvidos no processo de licitação de duas instituições federais de ensino, pesquisa e extensão. Considerando os aspectos singulares da administração pública e a complexidade das universidades, estabeleceram-se para a análise os constructos conhecimento, eficiência e eficácia dos fluxos processuais.

Perante o contexto explanado, o presente estudo tem como objetivo analisar, na percepção dos diferentes atores das compras públicas, a atuação, a eficiência e a qualidade dos processos licitatórios no âmbito de duas instituições federais de ensino.

O estudo é motivado pela carência de pesquisas na área específica de licitações, que consiste em um processo relevante e que movimenta 
bilhões de reais na administração pública federal, estadual e municipal. Ademais, consiste em um recorte inovador que ainda não foi abordado em pesquisas anteriores.

\section{Revisão da literatura}

Qualquer indivíduo ou empresa que precisa realizar determinado negócio busca fazê-lo a partir de proposta mais vantajosa. Para alguns, essa escolha é obrigatória e rígida; para outros, optativa e flexibilizada (DIAS, 2001).

No caso da administração pública, não há possibilidade do provimento de bens, serviços e obras ocorrerem diretamente, por isso esta, recorre ao mercado para sustentar suas atividades. Todavia, ela não adquire tais insumos da empresa ou pessoa que lhe achar conveniente, mas instaura processos de seleção baseados em regras preestabelecidas em lei específica. Esse procedimento denomina-se licitação.

Diferente das empresas privadas que visam o lucro, a finalidade da administração pública, é garantir o interesse da população, que contribui para o Estado na forma de impostos e deseja que estes sejam bem aplicados e distribuídos. Desse modo, o processo de aquisição na esfera pública busca seguir princípios constitucionais a fim de estabelecer isonomia e transparência, bem como melhor negociação - que não representa necessariamente melhor preço, e claramente o atendimento de suas demandas objetivando o interesse público.

\subsection{Licitações públicas}

A etimologia do termo "licitação" vem do latim licitatione, que representa o ato de licitar oferta de um ou mais lances em leilão. No Brasil, ao longo de muito tempo, usou-se para discriminar licitações o termo "concorrência pública". Basicamente, concebe-se o termo na abrangência de "qualquer procedimento que tenha finalidade de selecionar seja através de preço mais conveniente, seja através da 
qualidade mais adequada, ou de ambos, a melhor oferta de bens ou serviços oferecida ao Estado por particulares" (BEZERRA, 2008, p. 12).

De acordo com Meirelles (2005), licitação é prática executada desde a Idade Média, quando Estados medievais europeus empregaram um sistema conhecido então por "vela e pregão", que tratava de selecionar a obra desejada, e enquanto ardia uma vela, os construtores interessados realizavam seus lances. Quando o fogo cessava, a obra era adjudicada a quem houvesse oferecido melhor preço.

Filho (2002, p. 25) relata o início das licitações no Brasil: “A história da licitação no Brasil data de 1916 com o Código da Contabilidade Pública da União. Este codex foi substituído em parte pelo Decreto-Lei 200/67, ao dispor, entre os artigos 125 a 144, sobre licitações".

De acordo com Bottino (1998), o Decreto-Lei ${ }^{\circ} 2.300 / 86$, conhecido como Estatuto Jurídico das Licitações e Contratos, substituiu o DecretoLei $n^{\circ}$ 200/67. A maioria dos doutrinadores da época considerou-o um bom regulamento, pois abrangia com propriedade licitações e contratos públicos, todavia, existia um clima de denúncias de corrupção veiculadas pela mídia.

Em decorrência desse clima, deputados instauraram a tramitação do projeto-lei que originou a Lei $n^{\circ}$ 8.666/93, que estabelece regulamentos gerais e obrigatórios para a administração pública realizar suas aquisições e contratos. Tal lei foi baseada na Constituição, como forma de colocá-la em prática na administração pública.

O processo de licitação se insere no contexto de processo administrativo. Assim versa a Lei no 8666/93 em seu artigo 38 (BRASIL, 1993): "o processo da licitação será iniciado com abertura de processo administrativo". Desse modo, tem-se um grupo de formalidades que devem ser seguidas para o cumprimento e continuidade desse processo.

\subsubsection{Modalidades da licitação}

Segundo Fernandes (2008), desde o Decreto-Lei n² 200/67, ficaram regulamentadas no Direito Administrativo do Brasil cinco modalidades de 
licitação, sendo elas: convite, tomada de preços, concorrência, concurso e leilão. Foram a estas somadas duas: o pregão e a consulta, sendo que a última não cabe ser tratada neste estudo, por ser modalidade especifica para regulamentação das licitações da Anatel.

Aponta-se que, para critérios de julgamento das propostas, a lei prevê diferentes tipos ou alternativas de seleção, sendo elas: a de menor preço, melhor técnica ou ainda a combinação de menor preço com melhor técnica. É importante ressaltar também que a administração pública deve selecionar de acordo com cada situação a modalidade adequada ao objeto e ao valor a ser licitado.

Para desenvolvimento dos procedimentos licitatórios, faz-se nomeação de uma comissão de licitação composta por no mínimo três membros, sendo dois destes necessariamente pertencentes ao órgão responsável pela licitação.

Além dessas, há também a modalidade pregão, que consiste na mais recente delas e surgiu com a Medida Provisória $n^{\circ} 2.026$, de 4 de maio de 2000, aplicando-se à aquisição de bens e serviços comuns de qualquer valor e tem por objetivo facilitar trâmites dos procedimentos licitatórios, trazendo a estes maior faculdade de participação, bem como maiores flexibilização e transparência.

Nessa modalidade, designa-se um servidor para ser o pregoeiro, eliminando a necessidade de uma comissão, como ocorre nas demais modalidades. Durante a sessão pública de pregão, acontece oferecimento de propostas e lances, daí o dizer popular que "pregão é o oposto de leilão".

Em suma, pode-se analisar as características de cada modalidade de licitação a partir do Quadro 1. 
Quadro 1- Características de cada modalidade e diferença entre as normas

\begin{tabular}{|c|c|c|c|c|c|c|}
\hline Modalidades & Convite & $\begin{array}{c}\text { Tomada } \\
\text { de Preços }\end{array}$ & Concorrência & Leilão & Concurso & Pregão \\
\hline Prazo & 5 dias & $\begin{array}{l}15 \text { a } 30 \\
\text { Dias }\end{array}$ & 30 a 45 dias & 15 dias & 45 dias & 8 dias \\
\hline $\begin{array}{l}\text { Tipo de } \\
\text { Licitação }\end{array}$ & Todos & Todos & Todos & $\begin{array}{l}\text { Maior } \\
\text { lance/ } \\
\text { melhor } \\
\text { oferta }\end{array}$ & Técnica & $\begin{array}{l}\text { Menor } \\
\text { Preço }\end{array}$ \\
\hline $\begin{array}{l}\text { Obras e } \\
\text { Serviços de } \\
\text { Engenharia }\end{array}$ & $\begin{array}{l}\text { Até } R \$ \\
150.000\end{array}$ & $\begin{array}{l}\text { Até } \mathrm{R} \$ \\
1.500 .000\end{array}$ & $\begin{array}{l}\text { Acima de } \\
1.500 .000\end{array}$ & - & $\begin{array}{l}\text { Não tem } \\
\text { limite }\end{array}$ & $\begin{array}{l}\text { Não tem } \\
\text { limite }\end{array}$ \\
\hline $\begin{array}{l}\text { Compras e } \\
\text { Serviços }\end{array}$ & $\begin{array}{l}\text { Até R\$ } \\
80.000\end{array}$ & $\begin{array}{l}\text { Até } \mathrm{R} \$ \\
650.000\end{array}$ & $\begin{array}{l}\text { Acima de } \\
650.000\end{array}$ & - & $\begin{array}{l}\text { Não tem } \\
\text { limite }\end{array}$ & $\begin{array}{l}\text { Não tem } \\
\text { limite }\end{array}$ \\
\hline $\begin{array}{l}\text { Restrição ao } \\
\text { objeto }\end{array}$ & Não há & Não há & Não há & $\begin{array}{l}\text { Alienação } \\
\text { de bens }\end{array}$ & $\begin{array}{l}\text { Trabalho } \\
\text { técnico } \\
\text { cientifico } \\
\text { ou } \\
\text { artístico. }\end{array}$ & $\begin{array}{l}\text { Bens e } \\
\text { serviços } \\
\text { comuns }\end{array}$ \\
\hline Condução do ato & $\begin{array}{l}\text { Servidor } \\
\text { ou } \\
\text { comissão }\end{array}$ & Comissão & Comissão & $\begin{array}{l}\text { Pode ser } \\
\text { ou } \\
\text { não } \\
\text { servidor }\end{array}$ & Comissão & $\begin{array}{l}\text { Pregoeiro } \\
\text { e Equipe } \\
\text { de Apoio. }\end{array}$ \\
\hline $\begin{array}{l}\text { Fundamentação } \\
\text { legal }\end{array}$ & $\begin{array}{l}\text { Art. } 22 \text { da } \\
\text { lei } 8.666\end{array}$ & $\begin{array}{l}\text { Art. } 22 \text { da } \\
\text { lei } 8.666\end{array}$ & $\begin{array}{c}\text { Art. } 22 \text { da lei } \\
8.666\end{array}$ & $\begin{array}{l}\text { Art. } 22 \text { da } \\
\text { lei } 8.666\end{array}$ & $\begin{array}{l}\text { Art. 22da } \\
\text { lei } 8.666\end{array}$ & $\begin{array}{c}\text { Instituído } \\
\text { pela MP } \\
2026, \\
\text { alterada } \\
\text { pela MP } \\
2182 \text { e } \\
\text { convertida } \\
\text { na } \\
\text { L10520. }\end{array}$ \\
\hline
\end{tabular}

Fonte: Jacoby Fernandes (2008, p.161).

\subsubsection{Fases do procedimento licitatório e atores sociais envolvidos}

Para atingir seus objetivos, a licitação passa por determinados procedimentos ou fases que podem ser classificadas em: preparação, convocação, habilitação, competição e contratação, sendo os dois primeiros procedimentos internos realizados como atos preparatórios para ser realizada a competição, e as três últimas são fases externas. 
$\mathrm{Na}$ fase da preparação, que é realizada em sua totalidade internamente, os setores de compras atuam em conjunto com as áreas que tenham demandas de aquisições de bens ou contratação de serviços. Exige-se que em cada licitação seja nomeado o responsável por esta, que direciona o trabalho ao agente de compras (que pode ser um gestor ou coordenador da área). A necessidade de compra, o objeto, bem como a justificativa desta, comporá o termo de referência que será base para o edital. Em seguida, exige-se o levantamento de valor estimado do objeto junto ao mercado, bem como se verifica a disponibilidade orçamentária para sua aquisição.

Passados esses procedimentos, ainda na fase de preparação, elabora-se o edital, que consiste na peça-chave do processo, pois regulamenta todas as exigências e disposições dos procedimentos a serem adotados na licitação e trata-se do instrumento para convocação e publicidade desta.

A fase seguinte é denominada de "convocação" e se refere à divulgação do edital por meio de publicação de aviso em Diário Oficial, jornais ou portais de compras governamentais, com prazos mínimos fixados por lei para conhecimento e alcance de quaisquer interessados. O primeiro meio de veiculação citado (impressa oficial) é obrigatório, todavia, com o advento da internet e da tecnologia, tende-se para a publicação por meio da internet. No caso da administração pública federal, isto já ocorre, no portal comprasnet.

Tem-se também a fase da habilitação, que se trata da "verificação da capacidade do licitante em atender ao fornecimento a ser contratado, com base nos requisitos estabelecidos no edital" (Fernandes, 2008, p. $6)$.

A verificação da regularidade fiscal compreende-se em consultas às certidões negativas de débitos do licitante referentes à Seguridade Social, FGTS (Fundo de Garantia por Tempo de Serviço) e Fazenda Nacional. Exige-se ainda qualificação técnica, jurídica e de capacidade econômica. 
Todas essas fases levam morosidade ao processo. Em virtude desse fato, o pregão torna-se mais ágil, pois faz a verificação de habilitação somente do vencedor, e durante a competição. Assim, ocorre uma inversão de fases e evita que todas as empresas sejam consultadas, reduzindo prazos e aspectos burocráticos.

Outra fase, a de competição, pode ser compreendida como sessão pública, em que propostas são recebidas em lacres, sendo abertas, examinadas e julgadas pela comissão de licitação, seguindo regulamentos previstos no edital. Após o referido julgamento, os licitantes que se atêm aos critérios preestabelecidos são classificados. Esse evento público é previamente agendado e os participantes devem estar credenciados. No caso do pregão eletrônico, a sessão ocorre virtualmente e as propostas iniciais são submetidas à disputa por lances, em que propostas iniciais podem ser reduzidas.

Mostra-se, por fim, a fase de contratação, conhecida por adjudicação, que se refere à convocação do licitante vencedor para celebração do contrato. Caso o vencedor não compareça até o prazo definido no edital para assinatura das propostas, convoca-se o licitante que apresentou a segunda melhor proposta, e assim sucessivamente. Para que as cláusulas contratuais sejam aferidas com magnitude, é importante que o órgão faça boa gestão do contrato.

Antes da referida adjudicação, ocorre a homologação do resultado da licitação pela autoridade competente, que deve ratificar todos os procedimentos empregados na licitação, verificando se houve alguma irregularidade. Caso encontre tal ilegalidade, o homologador irá anular o processo licitatório, contudo, se estiver tudo dentro dos parâmetros da lei, pode este homologar o certame, ou ainda, se for de interesse público cabível, revogá-lo (BEZERRA, 2008).

Há de se destacar, por fim, que quando o montante estimado para alguma licitação, ultrapassar em cem vezes o valor mínimo da concorrência, obriga-se realização de audiência pública, a fim de divulgar a licitação pretendida consultando a população interessada a respeito desta. 
No caso do pregão presencial ou eletrônico, as fases se invertem e a fase de abertura de propostas antecede à de habilitação, assim como a de adjudicação ocorre antes da homologação. Tem-se ainda que, na sessão pública, as propostas iniciais são submetidas à disputa por lances, em que propostas iniciais podem ser reduzidas. Desse modo, entende-se que há mais uma fase, a de lances.

Para que a licitação ocorra, é preciso uma série de atores sociais envolvidos que antecedem, perpassam todas as fases e ainda acompanham os fatos posteriores ao processo licitatório. Na fase de identificação da demanda, diversos atores podem atuar, sinalizando-a para que o responsável pela requisição realize o pedido. O pedido deve ser aprovado demonstrando sua previsão de custos e disponibilidade financeira e orçamentária. Então, os agentes que atuam no setor de licitações e compras elaboram o edital, publicam e realizam o certame. O ordenador de despesas homologa ou adjudica (dependendo da modalidade) o processo em sua fase final. Depois, o produto ou serviço chegará ao órgão e o setor requisitante deve atestar se o produto está em conformidade com o solicitado. A autoridade do órgão deve, em alguns casos, nomear uma comissão para fiscalizar o contrato. No fim desse ciclo, todos os usuários do produto ou serviço ou cidadãos envolvidos no órgão usufrutuam do produto ou do serviço prestado.

\subsection{Universidades como organizações complexas}

Para Andrade (2002), as universidades possuem peculiaridades que refutam contribuições advindas da gestão convencional. Desse modo, estas devem ser estudadas como um tipo específico de organização complexa, com particularidades critérios e tecnologias de gestão distintos dos empregados em outras instituições, tanto públicas como privadas.

Sendo assim, as universidades públicas possuem uma estrutura diferenciada, complexa e fragmentada, com um modelo burocratizado, processos padronizados, elevada autonomia em suas unidades administrativas, dificuldade da operacionalização dos objetivos em 
decorrência desses serem definidos de forma ampla e colaboradores especializados com alto nível de autonomia para desenvolver suas atividades (HARDY; FACHIN, 1996). Nesse contexto, para observar a dinâmica do processo de compras nas universidades federais, é preciso considerar o ambiente complexo em que elas estão inseridas.

\subsection{Burocracia nos processos licitatórios}

O sistema de controle de gastos públicos e os primeiros procedimentos licitatórios surgiram na Europa Medieval, época em que prevalecia o modelo patrimonialista de administração pública. A Idade Média se caracterizava principalmente pela figura do monarca, que detinha poderes e decisões político-administrativas, favorecendo o clero e a nobreza. Esse modelo acompanhou os regimes feudal e monárquico (MOTTA; PEREIRA, 1986).

Mas na metade do século XIX a corrente burocrática se insurge como forma de combate à pessoalidade nas organizações. Pelas ideias de Max Weber (WEBER, 1982), avulta o ideário racionalista, com o objetivo de proteger o Estado do nepotismo e da corrupção que imperavam no sistema patrimonialista (MOTTA, 1994). Esse modelo administrativo apresenta características que atenderam às expectativas, pois naquela época o Estado era menos complexo que nos dias atuais.

Evidentemente, o Estado aumentou suas funções. Dessa forma, o mau uso do modelo burocrático o desvirtuou, provocando paralises e entraves relacionados ao gerenciamento. $\mathrm{O}$ que fora concebido para gerar agilidade transmutou-se em si da burocracia, conhecidas como "buropatias ou doenças da burocracia" (MENEGASSI, 2007). Verificase que a administração desfocada provoca na máquina pública desvios que emperram o processo administrativo. As licitações, ao utilizarem esse modelo administrativo, acabam apresentando vícios, como destaca Carvalho (2007, p. 120): "as decisões ficaram bastante restritas e com controles burocráticos excessivos, privilegiando o controle de processos ao invés do controle de resultados". 
Aqui se tem um viés conceitual, pois, de acordo com Fernandes (2003), o modelo burocrata de Max Weber é impessoal: composto para ser implementado por profissionais selecionados por meritocracia, que agem sem autonomia própria, aplicando as leis. Isso porque inseridos em organizações centralizadas, contidas em estruturas, as quais, por sua vez, são hierárquicas e compostas por autoridades delineadas. Todavia, o feixe conceitual da burocracia, ao ser impulsionado, pode não funcionar de forma tal qual pensado, face às demandas dos Estados modernos. É que a própria burocracia, pensada como sistema duradouro, torna-se frágil diante de mudanças.

Tem-se que, ao lado da aplicação da lei (atividade vinculada, mero cumprimento), avultam outras atividades cotidianas não previstas pelo sistema rígido da burocracia (decisões de vontade, discricionárias, meramente intelectivas). Daí o próprio serviço público carecer de algo mais que um cumpridor de lei profissional. Demanda servidores capacitados a tomar decisões; daí ser necessária a eles mais autonomia e delegação de responsabilidades, requerendo, por conseguinte, uma administração pública mais descentralizada.

Complementando o panorama descrito, Abdala (2008) diz que muitos dos agentes públicos que controlam as aquisições governamentais não possuem aperfeiçoamento adequado e formação jurídica suficiente para compreender o alcance da lei e do principio da razoabilidade. Sendo assim, atuam como meros aplicadores da lei dentro de um modelo administrativo que favorece ainda mais essa condição, e dessa forma acabam provocando prejuízos para própria instituição.

Em virtude de algumas disfunções do modelo burocrático, podemse verificar nitidamente, no dia a dia das licitações nos órgãos públicos, prejuízos em sua gestão. Como exemplo, pode-se destacar que muitas empresas optam por não disponibilizar seus produtos e serviços para venda no serviço público. Isso porque a empresa não se sente preparada para lidar com o custo de tal venda, uma vez que o pagamento pode ser muito demorado e/ou as exigências pode ser por demais elevadas. 
Disso desprende-se que o próprio órgão público fica prejudicado quando precisa da prestação de certos serviços e fornecimento de material de empresas exclusivas no mercado; ou ainda quando precisa de materiais disponibilizados por poucas empresas profissionalizadas. Assim, o próprio ato de escolha fica restrito, por não haver como fazer ampla pesquisa de preço; ademais, o processo fica ainda mais burocratizado, pela necessidade de justificativa.

Por outro lado, a administração pública da lei não pode furtar-se, sob pena de voltar ao modelo patrimonialista, favorecedor de determinados súditos. Há que se cumprir a lei, e na esteira dela, não faltam rusgas. Seja de fornecedores que veem na preterição de suas propostas "meros trâmites burocráticos" descumpridos, seja dos próprios servidos públicos cumpridores do edital, que o consideram "meio engessado de aquisição" (Abdala, 2008).

Acresce que muitos fornecedores, e a própria sociedade, veem o serviço público com determinados preconceitos e receios à realização e desempenho de suas atividades, julgando-o ineficiente e dotado de procedimentos ilícitos. Sentimentos gerados em demasia a um modelo burocrático ultrapassado e não funcional, e também em razão aos grandes números de casos de corrupção, que tanto desagrada à população. Nesse caso, a administração pública gravita no desafio de cumprir a legislação (ainda que implicando morosidade) e prestar serviço tomando decisões (para tornar o serviço eficaz e ágil).

É importante frisar que a administração pública brasileira busca a passagem do modelo burocrata de gestão para o modelo de administração gerencial, abandonando as perspectivas negativas do modelo burocrático. Entretanto, para que isso seja possível, é necessário que não só a lei se desprenda de suas limitações, mas principalmente que cada órgão, dentro de sua especificidade, busque os gargalos em seus processos e sistemas e foque em resultados. Mas esse é contrassenso assaz, porque se no modelo gerencialista (setor privado) há decisões pessoais por tratar-se de capitais próprios, no modelo público se trabalha 
com orçamento e dinheiro de contribuintes, logo, decisões bastante restritas e que devem ser premidas de seriedade e zelo.

Com o passar do tempo, os processos de compras governamentais também se tornaram mais complexos e ainda mais cruciais, sendo encarados como elemento estratégico na administração pública. Desse modo, ainda é importante que o Brasil compatibilize a evolução do Estado e sua administração gerencial com a do setor de compras públicas. Com efeito, o modelo de Estado gerencial é ideal para tornar a política de compras mais ágil e eficiente.

Frente a esse processo, a lei que rege o processo licitatório representa grande avanço para aplicação das licitações no país, entretanto, com os resquícios do modelo burocrático, impulsionou a perca da celeridade processual. Cumpre explicar que a própria cultura da administração pública estabelece o ritual processualístico que emoldura rigidamente ações. Isso posto, clama-se no sentido de promover mudanças efetivas na realização dos atos administrativos, com efeito necessário e adequado no processo e no sistema da máquina administrativa governamental para dar maior eficiência ao procedimento.

É preciso, pois, modernizar as atividades de um modo geral e cada instituição pode ser responsável por esse processo, e não sem menos importância é necessário valorizar e qualificar o servidor público para o desempenho de suas atividades. Buscar maneiras de agilizar o processo, sem deixar de seguir os parâmetros da lei, é torná-lo eficiente.

Esse procedimento traria ganhos de escala para a sociedade, que anseia por serviços públicos transparentes; além disso, esse proceder consiste em maneira de tornar a organização pública e sua cadeia de suprimentos mais idônea.

\subsection{Eficiência e eficácia na administração pública}

Eficiência, no sentido puro, pode ser delineada com base nos estudos de Pareto no que tange mercados competitivos. A otimização da eficiência preconizada pelo autor descreve pelo menos três dimensões 
a eficiência nas trocas, a eficiência na produção e a eficiência na composição do produto (ARAGÃO, 1997).

Na administração pública, o conceito de eficiência teve um marco legal, tornando-se um princípio jurídico acrescido ao artigo 37, caput, da Carta Magna a partir da emenda 19/1998. Essa emenda constitucional foi realizada na reforma gerencial, incluindo o princípio de eficiência aos demais princípios que regem a atividade administrativa e regulam as ações das organizações públicas e de seus respectivos agentes.

Desprende-se do princípio da eficiência que os órgãos e entidades da administração pública devem primar pela eficiência em sua gestão. Desse modo, espera-se que a administração possa aplicar seus recursos de maneira adequada de modo a produzir bons resultados, atendendo assim às demandas da sociedade com maior celeridade. Nessa dinâmica de Estado, está inserida também a concepção da administração gerencial, ao passo que a inclusão do princípio da eficiência sugere uma transformação da administração burocrática para administração gerencial. Esse novo modelo de gestão para administração pública segue a dinâmica das empresas privadas, buscando minimizar os custos de transação e aperfeiçoar os resultados a serem atingidos. Observa-se que a maior celeridade passa a ser possível a partir da concepção de um Estado menos burocratizado em seus processos e com uma maior preocupação em gerar resultados, o que na lógica das empresas privadas seria o lucro, mas que na administração pública pode ser entendido como o benefício gerado a seus usuários, ou seja, a população.

Para Meireles (2005, p. 60), o conceito de eficiência na administração pública "é o mais moderno princípio da função administrativa, que já não se contenta em ser desempenhada apenas com legalidade, exigindo resultados positivos para serviço público e satisfatório atendimento das necessidades da comunidade e de seus membros".

Nesse contexto, Catellie Santos (2004) asseveram que o conceito de eficiência deve vir atrelado ao de eficácia. Muito embora os termos "eficiência" e "eficácia" se confundam, para o autor, o conceito de 
eficiência está ligado aos métodos e as normas, ou seja, ao processo empreendido para atingir determinado resultado. Já a eficácia refere-se às ações e aos resultados atingidos.

Luchi e Carneiro (2006) complementam definindo como procedimento eficiente o uso adequado de recurso disponível para concretização de um objetivo e eficácia e procedimento eficaz aquele que atinge os efeitos esperados e metas a que se propôs.

Ademais, a eficiência pode ser compreendida a partir de uma associação entre o input real e o input padrão, cujo resultado tenderia a nulo, enquanto a eficácia pode ser entendida pela relação entre o output real e o output padrão, em que o resultado tenderia ao infinito (ARAGÃO, 1997).

Um terceiro conceito amplamente discutido quando se trata dessa temática é o de efetividade, que, no âmbito da administração pública, é definido por Castro (2006) como uma medida que verifica o grau em que se arrolam a eficiência e a eficácia na condução de reais benefícios à sociedade.

Conquanto, a inserção do princípio da eficiência no ordenamento jurídico representa um primeiro passo para a instalação da moderna teoria gerencial na administração pública brasileira (CASTRO, 2006). Ademais, cabe aos gestores públicos fornecerem respostas efetivas à sociedade, buscando, a partir desse princípio, atender às amplas demandas e anseios da população.

\section{Metodologia}

O trabalho se propõe a analisar o processo de compras no âmbito da administração pública a partir da percepção de seus diferentes usuários. A abordagem empregada no estudo foi a quali-quantitativa com uso de coleta, análise e agrupamentos de dados.

Para essa análise, foi elaborado um questionário com 12 perguntas referentes ao perfil dos participantes, seus respectivos conhecimentos 
acerca das licitações, bem como percepção de eficiência e eficácia do processo licitatório. As perguntas foram elaboradas na abordagem da escala likert, que consiste na métrica mais empregada nas ciências sociais para levantamentos de atitudes, opiniões e avaliações (MALHOTRA, 2001). A escala foi estabelecida em cinco categorias de análise, que vão de discordo totalmente (1) até concordo totalmente (5) e tratam do grau ou nível de concordância com cada série de afirmações referentes ao objeto da pesquisa.

Foram enviados 80 questionários para os usuários diretos e indiretos das licitações de duas instituições federais de ensino. Os questionários foram categorizados conforme o tipo de usuários, dessa forma a amostra foi dividido em quatro grupos. 44 questionários foram recebidos com as respostas, contudo nove foram invalidadas, por motivo de rasura ou ausência de preenchimento correto. Os grupos de atores foram separados metodologicamente conforme seu campo de atuação no procedimento licitatório (Quadro 2).

Quadro 2 - Atores sociais respondentes da pesquisa empírica

\begin{tabular}{|lll|}
\hline Grupo & Nomenclatura & Atores envolvidos \\
\hline 1 & Ordenador de Despesas & $\begin{array}{l}\text { Ordenador de Despesas ou Diretor Geral de } \\
\text { unidade/campus. }\end{array}$ \\
\hline 2 & Presidente da CPL & $\begin{array}{l}\text { Presidente da CPL, Chefe do Setor de Licitações ou } \\
\text { Pregoeiro. }\end{array}$ \\
\hline 3 & Requisitante & $\begin{array}{l}\text { Demandante responsável pela requisição de compra } \\
\text { e elaboração do Termo de Referência. }\end{array}$ \\
\hline 4 & Usuário & $\begin{array}{l}\text { Usuário direto do produto adquirido ou serviço } \\
\text { prestado. }\end{array}$ \\
\hline
\end{tabular}

Fonte: Elaborado pelo autor.

Quanto aos constructos avaliados na aplicação dos questionários, foram divididos em 4 categorias de análise, elencadas no Quadro 3. 
Quadro 03 - Categorias de análise

\begin{tabular}{|lll|}
\hline Categorias & Dimensões de análise & Método de análise \\
\hline $\begin{array}{l}\text { Perfil dos } \\
\text { entrevistados }\end{array}$ & $\begin{array}{l}\text { Papel desempenhado na instituição, } \\
\text { formação acadêmica, tempo como } \\
\text { servidor, cursos na área das licitações. }\end{array}$ & Estatística descritiva \\
\hline & $\begin{array}{l}\text { Conhecimento acerca dos } \\
\text { procedimentos para abertura e } \\
\text { acompanhamento de um processo de } \\
\text { Conuisição na Instituição; Conhecimento } \\
\text { acerca dos aspectos da Lei no 8.666/93, } \\
\text { quais são as fases e modalidades das } \\
\text { licitações públicas. }\end{array}$ & \\
\hline \multirow{3}{*}{ Eficiência } & $\begin{array}{l}\text { Tempo, agilidade na aquisição do de correspondência } \\
\text { produto, aspectos que envolvem os } \\
\text { meios processuais de aquisição. }\end{array}$ & Análise de correspondência \\
\hline \multirow{2}{*}{ Eficácia } & $\begin{array}{l}\text { Qualidade percebida dos produtos } \\
\text { e serviços prestados. Resultado do } \\
\text { processo de aquisição. }\end{array}$ & Análise de correspondência \\
\hline
\end{tabular}

Fonte: Elaborado pelo autor.

Foi testada a confiabilidade do questionário a partir do coeficiente Alfa de Cronbach, que consiste na mensuração do quanto os itens de um determinado instrumento estão correlacionados. O valor do alpha deve ser positivo, variando entre 0 e 1, e quanto mais elevado, maior será a consistência apresentada. O valor mínimo para se considerar o questionário confiável é 0,7 . Esse coeficiente foi preconizado por Lee J. Cronbach em 1951 (CRONBACH, 1951) e vem sendo amplamente empregado em pesquisas na área de ciências econômicas e sociais. $\mathrm{O}$ teste é empregado para análise de consistência interna. O cálculo do coeficiente se dá a partir da seguinte expressão:

$$
\frac{k}{k-1}\left(\frac{\sum_{i \neq j}^{k} \operatorname{cov}\left(x_{i}, x_{j}\right)}{\operatorname{var}\left(x_{0}\right)}\right)=\frac{k}{k-1}\left(1-\frac{\sum_{j=1}^{k} \operatorname{var}\left(x_{j}\right)}{\operatorname{var}\left(x_{0}\right)}\right)
$$

Os dados foram tabulados a partir de estatística descritiva e da análise de correspondência, também denominada ANACOR, que consiste em uma técnica de interdependência que busca associações entre variáveis qualitativas em um espaço multidimensional, o que 
permite demonstrar graficamente a natureza das relações em um mapeamento perceptual (HAIR et al., 2006).

Fávero et al. (2006) destacam que a ANACOR utiliza o teste $X^{2}$ para padronizar os valores das frequências e formar base para associações. Para tanto, são consideradas as diferenças entre as frequências observadas e esperadas; desse modo, o teste $X^{2}$ padroniza os valores das frequências e cria uma medida em distância métricas formando projeções ortogonais cujas categorias são alocadas representando um grau de associação gerado pelas distâncias $X^{2}$ em um espaço dimensional.

\section{Análise dos dados e discussão dos resultados}

A fim de mensurar a confiabilidade do questionário aplicado procedeu-se o cálculo do coeficiente Alfa de Cronbach. O valor do coeficiente foi de 0,768 quando considerados todos os constructos avaliados pela análise de correspondência e 0,708 quando considerados todos os itens ou perguntas da pesquisa. Dessa forma, a consistência interna do questionário pode ser considerada razoável, sendo que as escalas os constructos são adequados ao propósito em que foram designados.

As 36 respostas válidas foram tabuladas com procedimentos estatísticos. Quanto ao tempo de instituição, os dados são elencados na Tabela 1. Dos respondentes, a maioria $(38,89 \%)$ possui menos de cinco anos de instituição. Pode-se observar a incidência de menor tempo de atuação no grupo de usuários e de presidente da CPL e pregoeiros. No caso deste último, observa-se na instituição que novos há um grande número de novos servidores alocados no setor de licitações e, mesmo com pouco tempo de serviço desempenhado, já ocupam cargos relacionados à chefia e condução dos certames licitatórios. 
Tabela 1 - Tempo de instituição dos respondentes

\begin{tabular}{l|c|c}
\hline Tempo de Instituição & Frequência Absoluta & Frequência Relativa $\%$ \\
\hline Menos de 5 anos & 14 & $38,89 \%$ \\
De 6 a 10 anos & 8 & $22,22 \%$ \\
11 a 15 anos & 7 & $19,44 \%$ \\
16 a 25 anos & 6 & $16,67 \%$ \\
Mais de 25 anos & 1 & $2,78 \%$ \\
\hline Total & $\mathbf{3 6}$ & $\mathbf{1 0 0 , 0 0 \%}$ \\
\hline
\end{tabular}

Fonte: Dados da pesquisa.

Quanto à formação, a maioria dos respondentes possui nível de especialização, como pode ser observado na Tabela 2. Os níveis mais elevados de formação encontram-se no grupo de ordenadores de despesas e diretores gerais de unidade. Explica-se pelo fato de todos os ocupantes do mais elevado cargo da unidade ou campus serem professores e possuírem a titulação de doutorado.

Tabela 2 - Formação dos respondentes

\begin{tabular}{l|c|c}
\hline Formação & Frequência Absoluta & Frequência Relativa $\%$ \\
\hline Ensino Médio & 6 & $16,67 \%$ \\
Graduação & 3 & $8,33 \%$ \\
Especialização & 11 & $30,56 \%$ \\
Mestrado & 8 & $22,22 \%$ \\
Doutorado & 8 & $22,22 \%$ \\
\hline Total & 36 & $100,00 \%$ \\
\hline
\end{tabular}

Fonte: Dados da pesquisa.

A Tabela 3 elenca a quantidade de cursos e treinamentos realizados nos últimos dois anos acerca de licitações e contratos. Observou-se uma maior quantidade de treinamentos no grupo de presidentes da CPL e pregoeiros, sendo que estes foram apontados como treinamentos mais específicos, como o Curso de Formação de Pregoeiro e Elaboração de Editais. Já o grupo de ordenadores de despesas e diretores gerais evidenciou a participação em treinamentos mais gerais, como fórum e encontros periódicos para planejamento e discussão de melhorias. 
Tabela 3 - Treinamentos e cursos em licitações realizados pelos respondentes

\begin{tabular}{l|c|c}
\hline Descrição & Frequência Absoluta & Frequência Relativa \% \\
\hline Nenhum tipo de treinamento/curso & 4 & $11,11 \%$ \\
De 1 a 2 treinamento(s)/curso(s) & 9 & $25,00 \%$ \\
Mais de 2 treinamento(s)/curso(s) & 23 & $63,89 \%$ \\
\hline Total & 36 & $100,00 \%$ \\
\hline
\end{tabular}

Fonte: Dados da pesquisa.

Após a análise descritiva dos dados, foi realizada a análise de correspondência para as categorias do estudo. O mapa perceptual representado no Gráfico 1 verifica a aproximação entre o ator e seu nível de conhecimento em licitações. Para validação da análise de correspondência, foi procedido o teste qui-quadrado, que apresentou um resultado de 31,66 a um nível de significância de 0,01. As proporções das inércias das três dimensões foram 70,2\%, 27,5\% e 2,3\%, respectivamente. Percebe-se, a partir do mapa, que os ordenadores de despesa/diretores gerais e presidentes CPL/pregoeiros possuem mais conhecimento profundos (nível 5) acerca das licitações.

Gráfico1 - Mapa perceptual: tipo de ator e nível de conhecimento em licitações

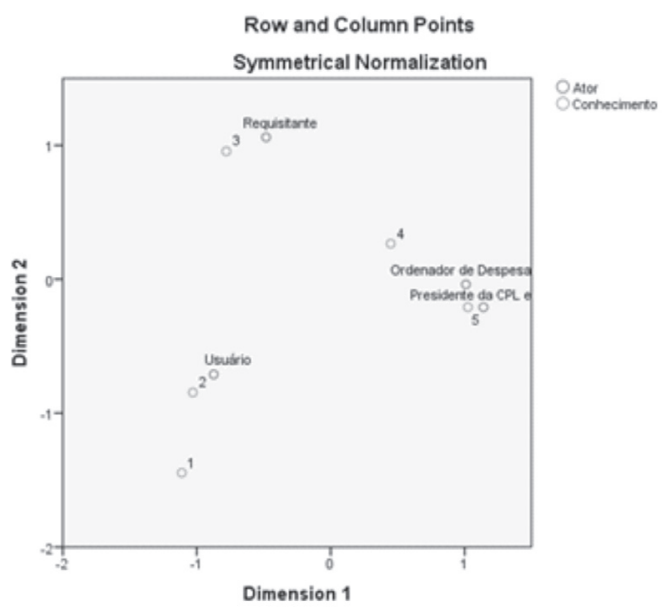

Fonte: Dados da pesquisa. 
Os dados evidenciam que a proximidade entre ordenadores de despesas e presidentes da área de licitações com o conhecimento do assunto parte de uma lógica natural. Mas o menor nível de conhecimento do requisitante pode representar um aspecto negativo, pois é esse ator social responsável pela elaboração do Termo de Referência que rege todo processo de compras e ainda seus momentos posteriores. A compra seguindo os preceitos de qualidade, economicidade e adequação do gasto público deve ser precedida de bons Termos de Referências, e para isso seu demandante deve possuir conhecimento necessário para realizá-lo de forma adequada. Quanto ao usuário, a distância deste do conhecimento do processo licitatório é preocupante, pois ele, usuário direto do produto ou serviço, é quem deve avaliar e criticar os aspectos concernentes ao seu uso, perante os preceitos de governança pública.

O Gráfico 2 demonstra que o mapa perceptual do tipo de ator do processo de compras versus o nível de eficiência que o respectivo ator percebe. A partir do eigenvalue (autovalores) de cada valor é possível identificar a contribuição de cada dimensão, demonstrando a variabilidade contida nos dados. As proporções de inércia para as 3 dimensões foram $65,1 \%, 32,9 \%$ e $2 \%$, respectivamente. Com o teste qui-quadrado de 42,62 (hipótese nula: as variáveis são independentes, ou seja, não há associação entre suas categorias) foi possível rejeitar a hipótese nula a um nível de significância de 0,001 e atender ao pressuposto subjacente ao uso da análise de correspondência. Pode-se inferir que ordenadores de despesa/diretores gerais e presidentes CPL/pregoeiros estão mais próximos da percepção da eficiência (celeridade e fluxo do processo licitatório) com um nível bom. Não obstante, os requisitantes e usuários se aproximam mais da percepção da eficiência como razoável e pouco eficiente respectivamente. Outro aspecto relevante é que nenhum dos grupos de atores aproxima-se da percepção da eficiência como excelente o que pode ser reflexo da percepção de morosidade e disfunções burocráticas inerentes ao processo licitatório. 
Gráfico 2 - Mapa perceptual: tipo de ator e nível de eficiência percebido

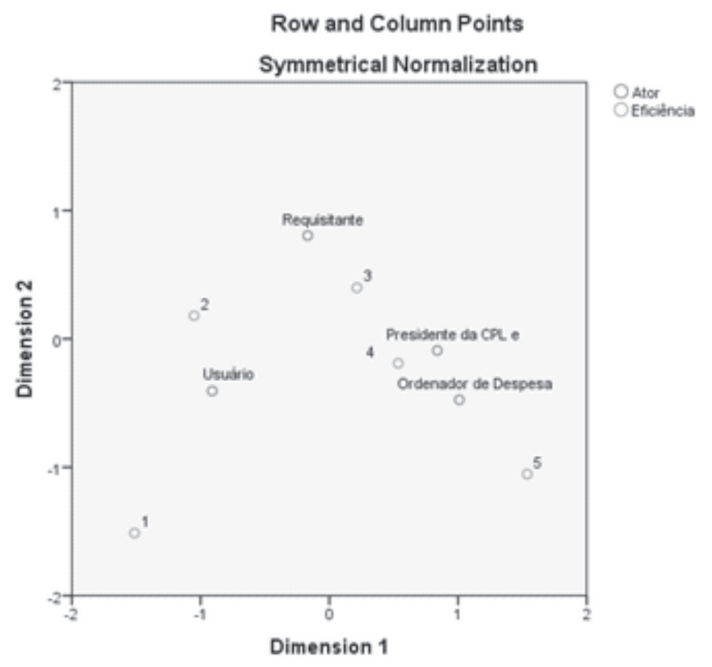

Fonte: Dados da pesquisa.

Por conseguinte, no Gráfico 3 é exposto o mapa perceptual do tipo de ator em relação à percepção de eficácia. O teste qui-quadrado apresentou o valor de 53,36 (sig a =0,001) validando o uso da ANACOR para análise em comento. Foram elencadas três dimensões com as contribuições em proporções de inércia de 48,4\%, 38\% e 13,6\%, respectivamente. A dimensão da eficácia representada pela qualidade dos produtos e serviços oriundos dos certames licitatórios apresenta uma maior aproximação entre o nível de percepção mais elevado e os grupos de ordenadores de despesa/diretores gerais e presidentes CPL/ pregoeiros. 
Gráfico 3 - Mapa perceptual: tipo de ator e nível de eficácia percebido

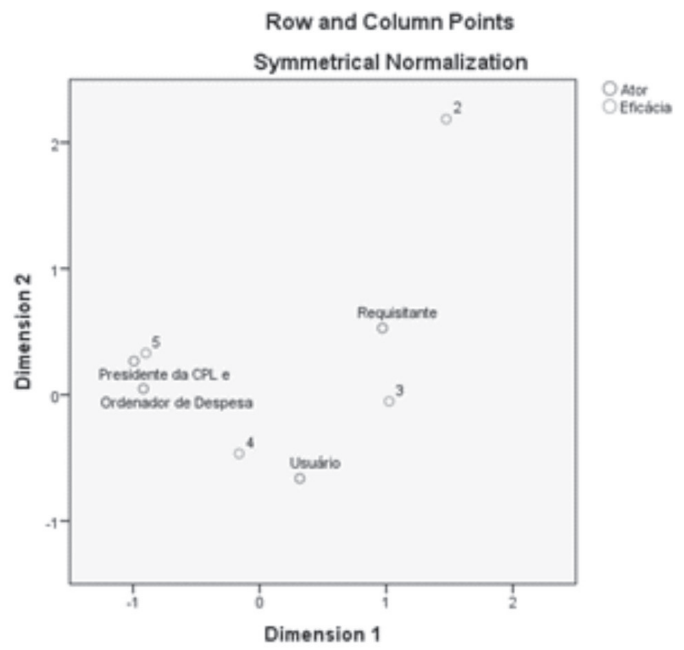

Fonte: Dados da pesquisa.

Por sua vez, a Tabela 4 demonstra a relação de aproximação entre o ator e a quantidade de cursos e treinamentos realizados. $O$ resultado do teste qui-quadrado foi de 27,11 a um nível de significância de 0,001. A proporção das inércias para as duas dimensões foram $89 \%$ e $11 \%$, respectivamente. Infere-se que os presidentes da CPL/pregoeiros estão mais associados à categoria 2 , que representa a realização de um a dois cursos/treinamentos. Outrora, os requisitantes e usuários estão mais próximos de nenhuma participação em cursos e treinamentos. 
Gráfico 4 - Mapa perceptual: tipo de ator e cursos/treinamentos realizados

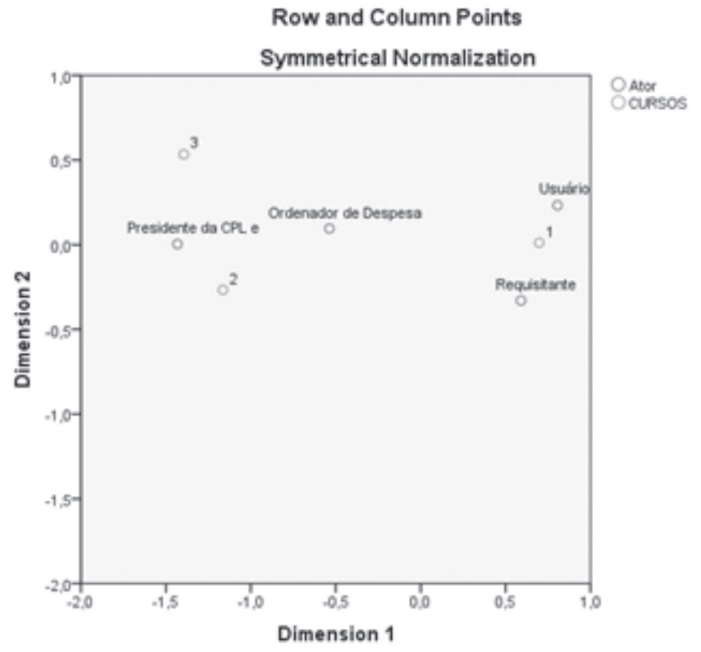

Fonte: Dados da pesquisa.

Chama-se atenção principalmente para o ator requisitante, que, como explanado anteriormente, deve conhecer bem os processos para que elabore requisições adequadas. No que se refere a essa pergunta, foi pedido para que o servidor explanasse o tipo de treinamento que considerava adequado. Os presidentes da CPL informaram cursos relacionados à área de compras sustentáveis que é uma nova temática em licitações. Já os requisitantes informaram cursos relacionados à elaboração de Termos de Referência. Por sua vez, os usuários não manifestaram respostas, sugerindo que desconhecem a necessidade de treinamentos na área ou temas relacionados a estes treinamentos.

\section{Conclusão}

O momento pelo qual passa o país requer que os gestores públicos, legisladores e cidadãos saibam se os recursos públicos estão sendo administrados adequadamente e em cumprimento aos preceitos legais. Precisam saber se os programas conduzidos pelas 
organizações governamentais estão atingindo os objetivos propostos e se as operações estão sendo econômicas e eficientes. (FALCÃO, 1997 apud LUCHI, 2006). Perante esse contexto, este trabalho teve o objetivo de: analisar, na percepção dos diferentes atores das compras públicas, a atuação, a eficiência e a qualidade dos processos licitatórios no âmbito de duas instituições federais de ensino.

De fato, o caminho a ser percorrido para que os processos sejam mais efetivos é longo, pois muitos são os entraves diante da administração pública brasileira que ainda carece de modernização e gerenciamento mais qualitativo. Contudo, os passos iniciais para tal desafio é cada órgão posicionar-se no sentido de oferecer melhorias constantes em seus processos gerenciais, o que passa por realização licitações bem preparadas e sucedidas.

As licitações, bem como o gerenciamento da administração pública brasileira, foram influenciadas pelo modelo burocrático, devido à sua capacidade em atender a complexidade do Estado moderno e acompanhar o desenvolvimento da economia monetária; e também devido à superioridade técnica que o modelo estabelece.

Tal modelo é baseado na racionalidade, o que é muito importante para conduzir profissionalização e impessoalidade dos funcionários a fim de garantir a eficiência da administração e propiciar o controle da coisa pública. De um lado, tem-se sua capacidade de eficiência e controle. Por outro lado, observa-se a alienação dos trabalhadores, o apego excessivo as normas e regulamentos, a perda da visão do todo. Com a evolução do Estado,adotaram-se medidas que buscassem atenuar as anomalias do modelo burocrático. Desse modo, o modelo gerencialista alinhado às boas práticas de governança pública foi crucial para o entendimento da demanda por um Estado mais flexível, focado no resultado e na transparência da gestão pública.

Nessa ótica, o estudo traçou algumas dimensões, como conhecimento, percepção de eficiência preconizada pelos elementos do modelo burocrático e eficácia preconizada pelos elementos do modelo de gerencialismo. As dimensões foram analisadas na visão 
dos diferentes atores envolvidos no processo de aquisições de duas instituições federais de ensino, pesquisa e extensão.

Um dos resultados identificados é que os atores que demandam licitações, delas não podem ficar alheios. Nessa concepção, levantou-se que é necessário melhorar a qualificação desses servidores (solicitantes, almoxarifes, coordenadores de curso) no que concerne a compras públicas, para que estes sejam envolvidos nesse contexto e apoiem os setores de licitações e compras, desenvolvendo termos de referencias e editais com especificações adequadas ao interesse da administração e da sociedade.

Identificou-se também que a eficiência percebida é regular na visão dos usuários e requisitantes. $O$ constructo eficiência foi dimensionado na ótica dos trâmites processuais e meios para atingir ao resultado, que seria a compra propriamente dita. Desse modo, ainda percebe-se trâmites com muitos elos, morosidade em alguns desses elos e jogos políticos para tornar o processo mais célere. Embora esses fatores sejam considerados entre os servidores como extremamente necessário para garantir a legalidade e transparência nos procedimentos, existem alguns pontos que podem ser melhorados, tais como o excesso de caminhos no qual transitam os processos.

Extrai-se desse panorama que o excesso de elos envolvidos nos trâmites apresenta duplicidade de ações e retrabalho. Com isso, o fluxo de ir e vir atreladas à necessidade de formalizar por escrito informações desnecessárias acaba levando à sacralização dos apêndices.

Desse modo, melhorias nos trâmites processuais, qualificação na base do processo e nos atores envolvidos com a elaboração do Termo de Referência e adoção de medidas de mensuração de desempenho podem melhorar o nível de eficiência e impactar diretamente na eficácia percebida que seria a concepção do produto final advindo da licitação. Nesse sentido, é importante que todos os atores envolvidos principalmente a sociedade, que também abrange uma série de atores da coisa pública - percebam a eficácia e a efetividade das contratações públicas. 
Este estudo apresentou algumas limitações quanto ao tamanho e seleção da amostra, que não permitem generalizações dos resultados, mas promovem reflexões instigantes acerca do tema abordado. Outro aspecto limitador são os vieses que podem ocorrer no momento da resposta aos questionários por parte dos respondentes. Contudo, tais limitações não ofuscam a contribuição da pesquisa para o desenvolvimento de pesquisas nas linhas processuais e nas práticas de gestão do dia a dia na administração pública. Outrora, sugere-se o empenho de novos estudos que ampliem as dimensões abordadas na presente pesquisa, com um maior tamanho de amostra e uma maior abrangência de órgãos públicos. Outros estudos nesse sentido ainda poderiam ser empreendidos, como: análise dos anseios e problemáticas da licitação na visão dos fornecedores; análise dos aspectos de economicidade em confronto com os aspectos de qualidade dos produtos e serviços; análise das dimensões verificadas neste estudo no entendimento da percepção de atores envolvidos em outros processos, tais como gestão de contratos, execução do orçamento público e gestão de materiais.

\section{Referências}

ABDALA, M. I. C. O que deve mudas na nova Lei de Licitações. [S.I.]. Disponível em: < http://licitacao.uol.com.br/apoio-juridico/artigos/6-oque-deve-mudar-na-nova-lei-de-licitacoes.html> . Acesso em 21 jan. 2014.

ANDRADE, A. R. A Universidade Como Organização Complexa. Revista de Negócios. Blumenau, v. 7, n. 3, p. 15-28, jul./set., 2002.

ARAGÃO, C.V. Burocracia, eficiência e modelos de gestão pública: um ensaio. Revista do Serviço Público, Brasília, v. 48, n. 3, p. 104-132, dez.1997.

BEZERRA, J. E. V. O Pregão eletrônico como base para minimizar custos da Gestão Pública. 2008. 59 f. Monografia (Graduação em Administração) - Centro Universitário de João Pessoa, João Pessoa, 
2008.

BOTTINO, Mariza. Arquivos universitários: repertório bibliográfico preliminar. Arquivo \& Administração, Rio de Janeiro, v.1, n.2, p.57-79, jul./dez. 1998.

BRASIL. Decreto $n^{\circ} 5.450$, de 31 de maio de 2005. Regulamenta o pregão, na forma eletrônica, para aquisição de bens e serviços comuns, e dá outras providências. Diário Oficial da União, Poder Executivo, Brasília, 1 jun. 2005. p. 5.

LLEI No 9.854, de 27 de outubro de 1999. Altera dispositivos da Lei n. 8666, de 21 de junho de 1993, que regula o art 37, inciso XXI, da Constituição Federal, institui normas para licitações e contratos da Administração Pública e dá outras providências. Diário Oficial da União, Seção 1, 28/10/1999, p.1.

. Lei $n^{\circ}$. 10.520, de 17 de julho de 2002. Institui, no âmbito da União, Estados, Distrito Federal e Municípios, nos termos do art. 37, inciso XXI, da Constituição Federal, modalidade de licitação denominada pregão, para aquisição de bens e serviços comuns, e dá outras providências. Diário Oficial da União, Poder Executivo, Brasília, DF, 18 jul. 2002. p. 1.

CARVALHO, H. V. S. Algumas irregularidades no âmbito do processo de licitação configuradoras de responsabilidade criminal. Revista Jurídica do Ministério Público, João Pessoa, ano 1, n.2, p. 116-131, jul./dez. 2007. Disponível em: <http://arquivos.mppb.mp.br/relatorios/rev02 juri_ mppb.pdf>. Acesso em 25 de jan. 2014.

CASTRO, R. B. Eficácia, eficiência e efetividade na administração pública? In: ENCONTRO ANUAL DA ASSOCIAÇÃO NACIONAL DOS PROGRAMAS DE PÓS-GRADUAÇÃO EM ADMINISTRAÇÃO DA ENANPAD, 30., 2006, Salvador. Anais... Salvador: ANPAD, 2006. $p$ 1-11 CD-ROM.

CATELLI, A.; SANTOS, E. S.. Mensurando a Criação de Valor na Gestão 
Pública. Rev. Adm. Pública (RAP), Rio de Janeiro, v. 38, n.3, p. 423449, maio/jun. 2004.

DIAS. A. C V. Licitação e desenvolvimento sustentável: o cooperativismo como uma resposta à questão social. 2001. $111 \mathrm{f}$. Monografia (Especialização em Análise de Políticas Públicas). Universidade Federal do Rio de Janeiro, Rio de Janeiro. 2001

FÁVERO, L. P.; BELFIORE, P.; DA SILVA, F. L.;CHAN, B. L.. Análise de dados: modelagem multivariada para tomada de decisões. Rio de Janeiro: Campus/Elsevier, 2009. 646p.

FERNANDES, J. U. J.. Contratação Direta sem Licitação. 7. ed. Belo Horizonte: Fórum, 2008.

FILHO C. C. R. et al. O grau de disfunção burocrática no Banco do Brasil. 2002. 77 f. Monografia (Especialização em Administração) - Programa de Capacitação Avançada, Universidade Federal da Bahia, Salvador. 2002.

FREITAS, M.; MALDONADO, J. M. S. V.. O pregão eletrônico e as contratações de serviços contínuos. Rev. Adm. Pública (RAP), Rio de Janeiro v. 47, n. 5, p.1265-281, set./out. 2013.

GUJARATI. D. Econometria básica. 4. ed. Rio de Janeiro: Elsevier, 2006.

HAIR JR, J.F.; ANDERSON, R.E.; TATHAM, R.L; BLACK, W.C.. Multivariate data analysis. 5th ed. New Jersey: Prentice Hall, 2006.

HARDY, C.; FACHIN, R. Gestão Estratégica na Universidade Brasileira: teoria e casos. Porto Alegre: UFRGS, 1996.

LUCHI, J. S. P; CARNEIRO, T. C. J.. Análise de eficiência e eficácia do pregão presencial. In: ENCONTRO NACIONAL DE ENGENHARIA DE PRODUÇÃO - ENEGEP, XXVI , 2006, Fortaleza. Anais... Fortaleza: ENEGEP, 2006. p. 1-9. 
MAFFINI, R.. Direito administrativo. 2 ed. São Paulo: Revista dos Tribunais. LFG. 2006.

MALHOTRA, N. K.. Pesquisa de marketing: uma orientação aplicada. 3. ed. Porto Alegre: Bookman, 2001.

MEIRELLES, H. L.. Direito Administrativo Brasileiro. 30. ed. São Paulo: Malheiros Editores, 2005.

MENEGASSI, C. H. M.. As dimensões do modelo burocrático nas organizações. 2007. $110 \mathrm{f}$.

Dissertação (Mestrado em Administração) - Universidade Estadual de Maringá, Maringá. 2007.

MOTTA, F. C. P.. O que é burocracia. 16. ed. São Paulo: Brasiliense, 1994.

MOTTA, F. C. P; PEREIRA, L. C. B.. Introdução à organização burocrática. 5. ed. São Paulo: Editora Brasiliense, 1986.

OLIVEIRA, C. M. O Valor Escondido das Compras Públicas. Portugal, 2008. Disponível em: <http://www.leadership-bg.com/index. php?option=com_content $\&$ view=article $\& i d=322 \&$ catid $=71 \&$ Itemid=86\&l ang=pt>. Acesso em 13 de maio 2009.

MILLS, W.; GEERT, H. H. (Orgs.). Max Weber: ensaios de sociologia. Tradução de Waltensir Dutra. 5ed. Rio de Janeiro: Zahar, 1982, 503 p.

Artigo recebido em: 07/03/2015

Aprovado em: 16/06/2015 